\title{
Rush Rodding of Femur in a Child with Osteogenesis Imperfecta Under Caudal Anaesthesia and Sedation: A Case Report
}

\author{
Shiyad Muhamed ${ }^{*}$, Ajith Kumar Pillai ${ }^{2}$, Shaji Mathew ${ }^{3}$, Arunkumar Handigodu Duggappa ${ }^{4}$ \\ ${ }^{1,2,4}$ Associate Professor, ${ }^{3}$ Professor, Kasturba Medical College, Manipal Academy of Higher \\ Education, Manipal, India
}

\begin{abstract}
Osteogenesis imperfecta presents with unique challenges to the anaesthetist. We report a case of osteogenesis imperfecta, posted for rush rodding of femur managed with caudal anaesthesia and sedation with dexmedetomidine and ketamine.
\end{abstract}

Key words: osteogenesis imperfecta, caudal anaesthesia, dexmedetomidine

\section{Introduction}

Osteogenesis imperfecta $(\mathrm{OI})$ is a rare connective tissue disorder caused by mutations of the collagen type I - COLIA 1 and COLIA 2 genes. ${ }^{1}$ The disease is characterised by fragile bones, hyperextensible joints, blue sclera, improper dentition, and progressive hearing loss. ${ }^{2}$ OI is classified into four types according to silence classification. $^{3}$

We present a known case of osteogenesis imperfect posted for rush rodding of femur successfully managed using caudal anaesthesia and sedation using dexmedetomidine infusion.

\section{Case report}

An 8-year-old boy, known patient with osteogenesis imperfecta type 1 , weighing $10 \mathrm{~kg}$ was posted for rush rodding of femur. He had recurrent episodes of fractures for which he was operated two years back under general anaesthesia. There was no other significant history in the past.

On examination his vitals were stable. He was short in stature, had blue sclera, pectus excavatum and kyphoscoliosis. Airway examination revealed mallampati class II with restricted neck movements.

*Correspondence: Shiyad Muhamed

E mail: shiyad82@gmail.com

https://orcid.org/0000-0003-4431-2324

Received: 24/12/2020

Accepted: 22/08/2021

DOI: https://doi.org/10.4038/slja.v29i2.8749
Rest of the examination findings were normal. Blood investigations including liver function tests and coagulation profile were normal. Cardiac evaluation including echocardiogram was normal.

In view of the possible instability of cervical spine, we decided to do the case under caudal anaesthesia and sedation using dexmedetomidine and ketamine. After noting down the baseline vitals, intravenous ketamine $1 \mathrm{mg}$ was given. The child was carefully positioned, and caudal anaesthesia was performed using $3 \mathrm{ml}$ of $2 \%$ lignocaine with adrenaline and $7 \mathrm{ml}$ of $0.25 \%$ bupivacaine. The child was positioned supine carefully with adequate padding and was sedated using dexmedetomidine infusion with a loading dose of 10 microgram over 15 minutes and maintenance dose of 5 microgram per hour. The surgery lasted for two hours. The child remained haemodynamically stable throughout the procedure.

\section{Discussion}

OI is the most common skeletal dysplasia occurring in approximately 1 in 20,000 births. The common feature of most of the cases is a gene mutation that leads to defective collagen formation leading to weakening of connective tissue. $^{4}$

The anaesthetic challenges in OI include difficult airway, susceptibility to fractures, risk of odontoaxial dislocation and breaking or displacement of fragile teeth during laryngoscopy and intubation.

Positioning the patient with OI is another important concern. ${ }^{5}$ Adequate padding of pressure points and careful handling of these patients play a very important role in the 
successful management of these patients. We ensured adequate padding at pressure points and careful handling especially during the injection of local anaesthetic for caudal block.

Use of regional anaesthesia helps to avoid the complications related to difficult airway. Regional anaesthesia, especially central neuraxial anaesthesia in these patients can be challenging owing to the possibility of platelet dysfunction and presence of spine abnormalities. ${ }^{6}$

We anaesthetised this child with caudal epidural so that we could avoid airway manipulation and complications related to the same. Moreover, positive pressure ventilation may worsen the already present ventilation perfusion mismatch in patients with OI. We chose dexmedetomidine as the sedative agent since it provides excellent hemodynamic conditions and minimal interference to ventilation.

\section{Conclusion}

We conclude that caudal anaesthesia with sedation is an alternative technique for anaesthetic management for lower limb surgeries in paediatric patients with osteogenesis imperfecta.

\section{References}

1. Stephen J, Shukla A, Dalal A, Girisha KM, Shah H, Gupta N, et al. Mutation spectrum of COL1A1 and COL1A2 genes in Indian patients with osteogenesis imperfecta. Am J Med Genet A 2014; 164A:1482-9.

2. Gupta D, Purohit A. Anaesthetic management in a patient with osteogenesis imperfecta for rush nail removal in femur. Anesth Essays Res 2016; 10: 677-9.

3. Sillence DO, Senn A, Danks DM. Genetic heterogeneity in osteogenesis imperfecta. J Med Genet 1979; 16:101-16.

4. Oakley I, Reece L. Anaesthetic implications for the patient with osteogenesis imperfecta. AANA J 2010; 78:47-53.

5. Libman RH. Anaesthetic considerations for the patient with osteogenesis imperfecta. Clin Orthop Relat Res 1981; 159:123-5

6. Garg M, Jain M, Gupta A. Anaesthetic management of a case of osteogenesis imperfecta with urinary bladder stone - A case report. Indian J Anaesth 2009; 53:68-70. 